\title{
Evaluation Of Stress Concentration Factors In Plate With Oblique Hole
}

\author{
B.C.Patle ${ }^{1}$, Dr. D.V. Bhope ${ }^{2}$ \\ ${ }^{1}$ PG Student, ${ }^{2}$ Professor, of Dept of Mechanical Engineering Rajiv Gandhi College of Engineering, Research \\ and Technology, Chandrapur (M.S.) India
}

\begin{abstract}
The paper reports the stress concentration factors in plate with oblique hole using FEM. Various angles of hole obliquity have been considered to evaluate SCF at such holes. The results are compared with photoelastic analysis results reported by $H . W$. McKENZIE and D. J. WHITE ${ }^{1}$ on the basis of gross area and net area.
\end{abstract}

Keywords: Finite Element Method, Oblique Hole, Stress Analysis.

\section{Introduction}

Localized stress around geometric discontinuities such as holes, shoulders, and grooves cannot be predicted accurately using elementary stress formulas. The concentration of stress resulting from these abrupt transitions is frequently too high to be attributed solely to the decrease in net cross sectional area. Stress concentration factors, often determined experimentally or computationally, are used to scale the nominal stress in a continuous structure to account for the effect of the discontinuity. Stress analysis of thick flat plate with oblique hole subjected to axial tension has been carried out using the finite element method (FEM).

An oblique may be defined as one having its axis at an angle with respect to the normal to a surface. At the intersection with a plane surface an oblique cylindrical hole gives rise to an elliptical trace and produces an acute angled edge which, for large angles of obliquity with respect to the normal, may be very sharp. Such holes are, for example, commonly found at interpenetrations in pressure vessels and as lacing-wire passages in steam turbine blades.

\section{Stress Concentration Factors}

It is convenient to express stresses in non-dimensional form. However, there is usually more than one reference stress which may be used for this purpose and the resulting stress-concentration factors $(S C F)$ may be seen to have merit for particular purposes. Since more than one definition is used here, the matter will be considered before the results are presented.

Definition 1:

$$
S C F=\frac{\text { Maximum Stress at Hole }}{\text { Nominal Stress Based on Gross Cross-section }}
$$

The gross cross-section is the section area obtained when the presence of the hole is ignored. This presentation is useful to the designer in that he multiplies the gross area stress by the $S C F$ from the graph and obtains the maximum stress at the hole. It has the disadvantage that it often gives the impression that very high stress concentrations exist whereas a large part of the factor may simply represent the ratio of gross area to net area. Thus, though of practical value, this form of presentation does not discriminate between stress intensification due to area decrease and that due to the true stress-concentration effect.

Definition 2:

Maximum Stress at Hole

$$
S C F=
$$

Nominal Stress Based on Net Cross-section

The net cross-section is the gross area minus the hole area including the portion removed by application of any apex radius. This presentation gives true stress-concentration effects uncomplicated by area changes. However, in some cases it is perhaps less useful to the designer for, whereas in the first definition the lower the $S C F$ the lower will be the maximum stress, in the second definition it may not be assumed that a lower $S C F$ will necessarily give a lower maximum stress. This is because the nominal stress based on the net area will vary as geometrical parameters of the discontinuity are changed, whereas the nominal stress based on gross area will remain constant. 
III. Introduction to Problem

The photoelastic analysis by H. W. McKENZIE and D. J. WHITE ${ }^{1}$, reports the experimental work for determination of stress concentration in an oblique hole in flat plate with thickness of $5 \mathrm{~mm}$, width of $97 \mathrm{~mm}$ and overall length of $254 \mathrm{~mm}$ as shown in Figure 1. The hole diameter(d) is $9.5 \mathrm{~mm}$ and four angles of obliquity with respect to normal are considered as, $\varnothing=30^{\circ}, 50^{\circ}, 65^{\circ}$ and $75.5^{\circ}$. Tension loading is applied in the direction of the length of the specimen and the stresses are frozen in the model. These same geometrical parameters of plate are considered for present work. The experimental results are verified using FE approach.

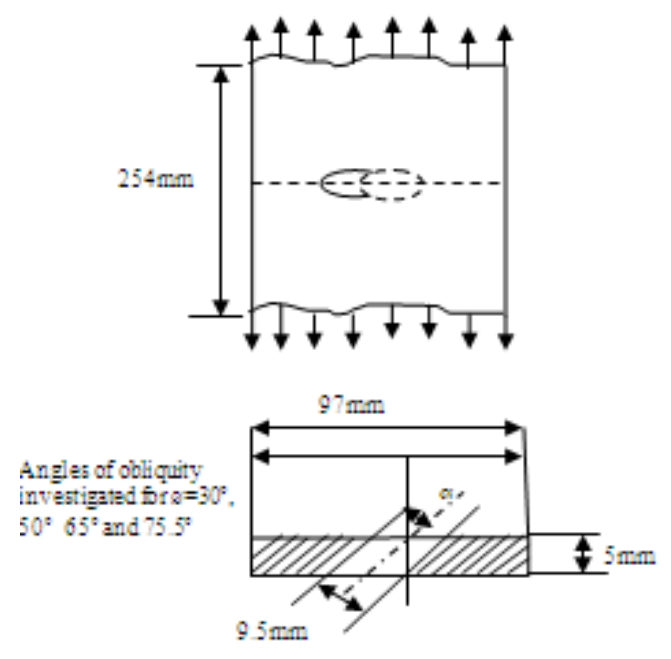

Figure 1: Model Detail

To determine the stresses in a plate, a plate under tensile load is considered. Finite element method is used with 3D element. The plate is assumed to be constrained at one end and loaded at other end. The stresses in a plate are also evaluated by considering a 2-D plate with elliptical hole formed due to obliquity.

\section{FE Analysis of Plate with Oblique Hole}

The values of Maximum Von-Misses stresses for different angles of obliquity are given in table 1 and maximum Von misses stress contours are shown in figure 2 to figure 6.

Table: 1 Von-Misses Stresses for Different Angles of Obliquity

\begin{tabular}{|l|c|c|c|c|c|}
\hline Angle of Obliquity $\left(\varnothing^{0}\right)$ & $0^{0}$ & $30^{0}$ & $50^{0}$ & $65^{0}$ & $75.5^{0}$ \\
\hline Von-Misses Stress (MPa) & 3.042 & 3.889 & 5.393 & 9.083 & 18.26 \\
\hline
\end{tabular}
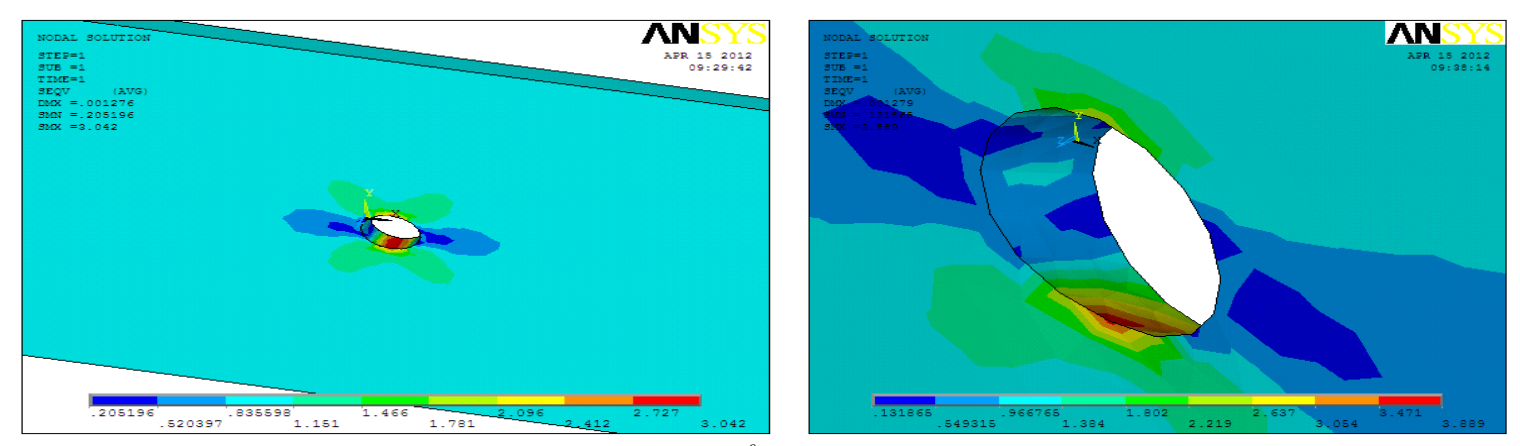

Figure 2: Von-Misses Stress Contour for Angle of Obliquity $\phi=0^{\circ} . \quad$ Figure 3 Von-Misses Stress Contour for Angle of Obliquity $\phi=30^{\circ}$

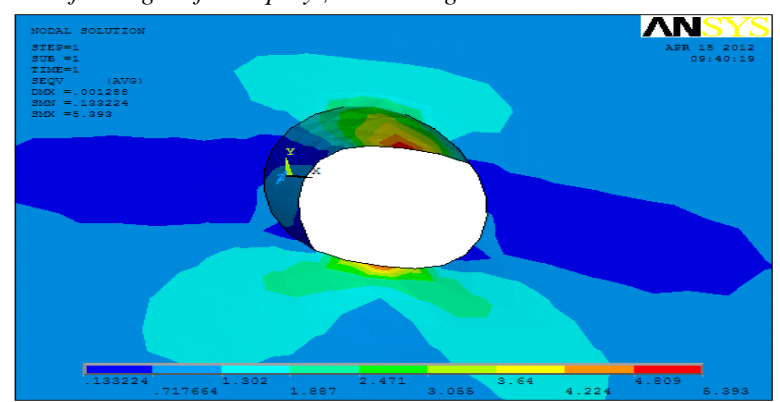

Figure 4 Von-Misses Stress Contour for angle of obliquity $\phi=50^{\circ}$. 


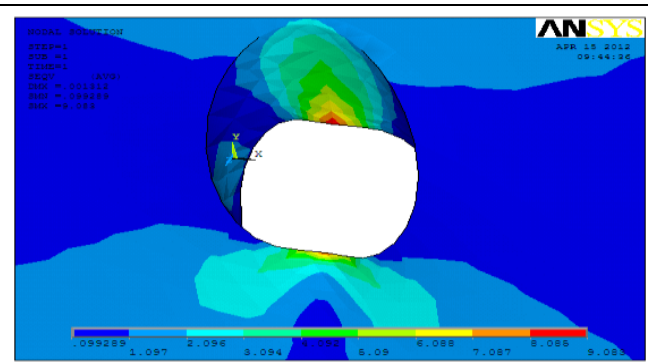

Figure 5 Von-Misses Stress Contour for angle of obliquity $\phi=65^{\circ}$

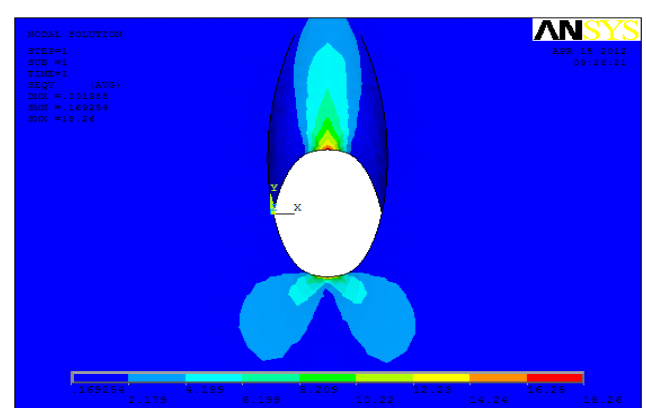

Figure 6. Von-Misses Stress Contour for angle of obliquity $\phi=75.5^{\circ}$

\section{Comparison between FE and Experimental SCF Based On Gross Area}

The Von-misses stresses for 3D plate with oblique hole and 2D plate with elliptical hole are given in table 2 .

Table 2: The Von-Misses stresses for 3D plate and 2D plate

\begin{tabular}{|l|l|l|l|l|l|}
\hline \multirow{2}{*}{ Plate type } & \multicolumn{5}{|c|}{ Von - Misses Stress (MPa) } \\
\cline { 2 - 6 } & \multicolumn{5}{|c|}{ Angles obliquity } \\
\cline { 2 - 6 } & $0^{0}$ & $30^{0}$ & $5^{0}$ & $65^{0}$ & $75.5^{0}$ \\
\hline FE stress for 3D plate with oblique hole & 3.042 & 3.889 & 5.393 & 9.083 & 18.26 \\
\hline FE stress for 2D plate with elliptical hole & 2.576 & 3.345 & 4.2198 & 6.047 & 10.753 \\
\hline Analytical stress for 2D plate with elliptical hole & 2.98 & 3.716 & 4.858 & 7.503 & 14.75 \\
\hline
\end{tabular}

Stress concentration factor is calculated by equation (1),

$$
S C F=\frac{\text { Maximum Stress at Hole }}{\text { Nominal Stress Based on Gross Cross-section }}
$$

Table 3 shows the stress concentration factor for above mentioned results.

Nominal stress is based on the gross area and calculated as $\sigma=1.666 \mathrm{MPa}$ for 3D plate and 1.107 MPa for 2D plate. The FE and experimental results for 2-D Plate with elliptical hole and 3-D Plate with oblique hole are compared in table 3 , and its variation is shown in figure 7.

Table: 3 Comparisons between FE and Experimental SCF

\begin{tabular}{|l|l|l|l|l|l|}
\hline \multirow{2}{*}{ Type of plate } & \multicolumn{5}{|c|}{ Stress Concentration Factor } \\
\cline { 2 - 7 } & \multicolumn{5}{|c|}{ Angles of obliquity } \\
\cline { 2 - 7 } & $00^{0}$ & $30^{0}$ & $50^{0}$ & $65^{0}$ & $75.5^{0}$ \\
\hline SCF for 3D plate with oblique hole(FE) & 1.825 & 2.334 & 3.23 & 5.45 & 10.96 \\
\hline SCF for 3Dplate with oblique hole(Expt.) & 2.9 & 3.7 & 5.1 & 7.3 & 11.5 \\
\hline SCF for 2D plate with elliptical hole(FE) & 2.32 & 3.02 & 3.81 & 5.45 & 9.71 \\
\hline SCF for 2D plate with elliptical hole(Expt.) & 2.9 & 3.6 & 4.2 & 6.0 & 9.2 \\
\hline SCF for 2D plate with elliptical hole( Analytical) & 2.69 & 3.35 & 4.38 & 6.77 & 13.32 \\
\hline
\end{tabular}




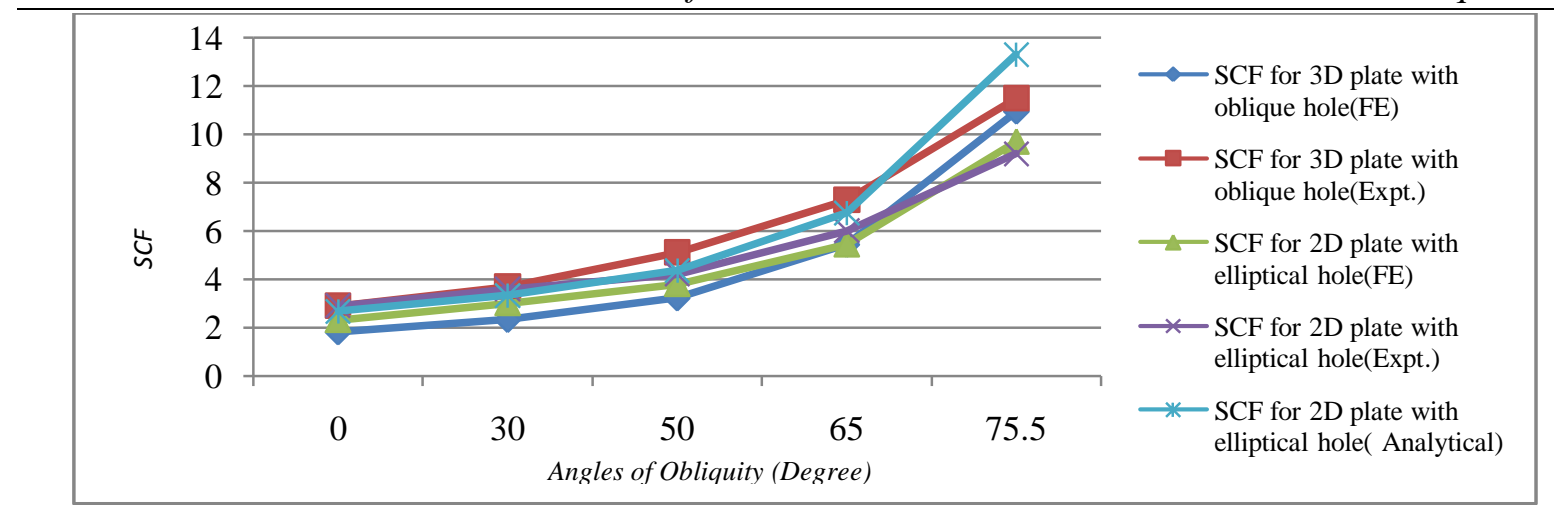

Figure 7: SCF vs. Angles of Obliquity

\section{Comparison between FE and Experimental SCF Based On Net Area} table 4.

The Von - Misses stresses for 3D plate with oblique hole and 2D plate with elliptical hole are given in

Table 4: Von-Misses stresses for 3D plate and 2D plate

\begin{tabular}{|l|l|l|l|l|l|}
\hline \multirow{2}{*}{ Plate type } & \multicolumn{5}{|c|}{ Von - Misses Stress (MPa) } \\
\cline { 2 - 7 } & $0^{0}$ & $30^{0}$ & $5^{0}$ & $65^{0}$ & $75.5^{0}$ \\
\hline FE stress for 3D plate with oblique hole & 3.042 & 3.889 & 5.393 & 9.083 & 18.26 \\
\hline FE stress for 2D plate with elliptical hole & 2.576 & 3.345 & 4.2198 & 6.0471 & 10.753 \\
\hline Analytical stress for 2D plate with elliptical hole & 2.98 & 3.716 & 4.858 & 7.503 & 14.75 \\
\hline Analytical nominal stress based on net area & 1.107 & 1.109 & 1.1273 & 1.304 & 1.643 \\
\hline
\end{tabular}

Stress concentration factor is calculated by equation (2),

$$
S C F=\frac{\text { Maximum Stress at Hole }}{\text { Nominal Stress Based on Net Cross-section }}
$$

Table 5 shows stress concentration factor for above mentioned results. Nominal stress is based on the net area given in table 4. The FE and experimental results for 2-D Plate with elliptical hole and 3-D Plate with oblique hole are compared in table 5 , and its variation is shown in figure 8.

Table 5: Comparison between FE and Experimental SCF

\begin{tabular}{|l|l|l|l|l|l|}
\hline \multirow{2}{*}{ Type of plate } & \multicolumn{5}{|c|}{ Stress Concentration Factor } \\
\cline { 2 - 6 } & \multicolumn{5}{|c|}{ Angles of obliquity } \\
\cline { 2 - 6 } & $0^{0}$ & $30^{0}$ & $50^{0}$ & $65^{0}$ & $75.5^{0}$ \\
\hline SCF for 3D plate with oblique hole(FE) & 2.72 & 3.44 & 4.57 & 6.96 & 11.11 \\
\hline SCF for 3Dplate with oblique hole(Expt.) & 2.8 & 3.2 & 4.3 & 5.5 & 7.3 \\
\hline SCF for 2D plate with elliptical hole(FE) & 2.32 & 2.96 & 3.57 & 4.63 & 6.54 \\
\hline SCF for 2D plate with elliptical hole(Expt.) & 2.7 & 3.1 & 3.6 & 4.5 & 6.0 \\
\hline SCF for 2D plate with elliptical hole( Analytical) & 2.68 & 3.29 & 4.11 & 5.75 & 8.97 \\
\hline
\end{tabular}

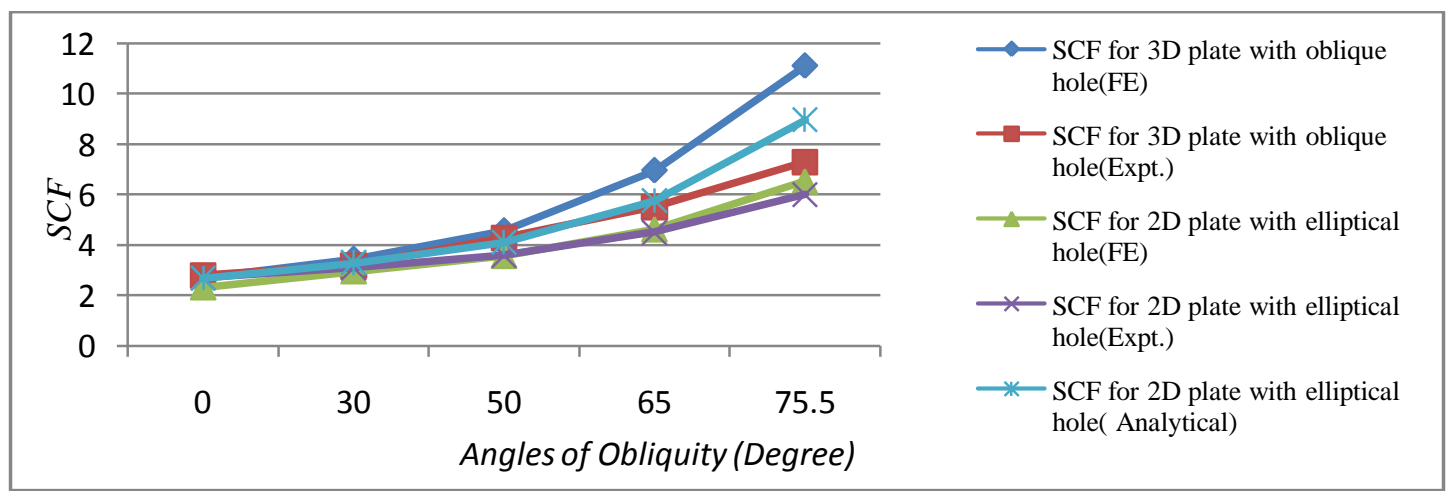

Figure 8: SCF vs. Angles of Obliquity 


\section{Discussion and Conclusion}

With reference to the results presented earlier, the discussions and conclusions are as follows.

1. A series of thick flat plates with oblique holes under axial tension is analysed using the finite element method. For the axial loading case, the stress concentration factors are compared with results obtained by the experimental photoelastic technique, as shown in Table2, Table 3, Figure 7, Table 4, Table 5, and Figure 8. For the $S C F$ values, the differences between the FE results and experimental results based on net area are within 5\% to 10\%, which showed good agreement. Models with holes at large angles of obliquity required large numbers of elements in order to achieve reliable results, but such numbers of elements are found to be beyond the limitations on computer time and space. For $\varnothing=60^{\circ}$ to $80^{\circ}$, the accuracy of FE results is very poor and the difference between the FE and experimental result is observed to be $25 \%$ to $35 \%$.

2. Figure 2 show the stress distribution around the hole for $\emptyset=0^{0}$. It is seen from figure that maximum stress is equally distributed along the thickness the hole.

3. Figure 3 shows the stress distribution around hole for angle of obliquity $\varnothing=30^{\circ}$. It is seen that the maximum stress is concentrated towards the one of the edge of hole. From figure 4, 5, 6, it is seen that maximum stress increases with increasing obliquity of hole.

4 Figure 7 shows that the comparison between FE and experimental results for 3D plate with oblique hole and the comparison between FE, experimental and analytical results for 2D plate with elliptical hole based on gross area. The $S C F$ values of the finite element analysis differ from those of the photoelastic work. Figure 7 shows the same trends for both the FE and experimental work.

5 Figure 8 shows that the comparison between FE and experimental results for 3D plate with oblique hole and the comparison between FE, experimental and analytical results for 2D plate with elliptical hole based on net area. From fig. 8 it is seen that for small obliquity of the hole, results are nearly same but as obliquity of the hole increases then result varies and this variation is large for large obliquity of the hole.

\section{References}

[1] McKENZIE D. J. WHITE "Stress concentration caused by an oblique round hole in a flat plate under uniaxial tension." Journal of Strain Analysis, Vol 3, No 2,1968

[2] P Stanley and A G Starr has find out "Stress concentration at an oblique hole in a thick plate”. Journal of Strain Analysis, Vol 35, No 2, 2000.

[3] A Tafreshi and T.E.Thorpe "Numerical analysis of stresses at oblique holes in plate subjected to tension and bending". Journal of Strain Analysis, Vol 30, No 4, 1995. 